МЕНЕДЖМЕНТ

\title{
ПРОБЛЕМА ЛИДЕРСТВА В СОВРЕМЕННОМ МЕНЕДЖМЕНТЕ
}

\author{
В. И. Колношенко, О. В. Колношенко \\ (Московский гуманитарный университет)
}

\begin{abstract}
Аннотация: В статье анализируются теоретические и практические аспекты лидерства в менеджменте. Обосновывается актуальность проблемы лидерства, степень ее разработанности в научной и учебной литературе. Раскрываются сущностные признаки лидерства в менеджменте, даются рекомендации по диагностике и развитию лидерских качеств у студентов - будущих менеджеров.

Ключевые слова: лидерство, лидер, менеджмент, менеджер, руководство, руководитель, теории лидерства, лидерские качества, диагностика лидерства, развитие лидерства.
\end{abstract}

\section{THE PROBLEM OF LEADERSHIP IN MODERN MANAGEMENT}

\author{
V. I. Kolnoshenko, O. V. Kolnoshenko \\ (Moscow University for the Humanities)
}

\begin{abstract}
This paper analyzes the theoretical and practical aspects of leadership in management, with a special emphasis on the urgency of this issue and its discussion in both research works and textbooks. We reveal the quintessential features of leadership in management, also providing recommendations for assessing and developingleadership qualities in management majors.

Keywords: leadership, leader, management, manager, leadership, administration, leadership theory, leadership qualities, assessing leadership, leadership development.
\end{abstract}

Лидерство представляет собой проблему, имеющую большое научное и практическое значение. Ее философское осмысление началось еще в древние времена. Однако объектом исследования и экспериментов лидерство стало лишь в начале двадцатого столетия. В 1930-1950 гг. был предпринят ряд крупномасштабных исследований лидерства на системной основе. Основателями первых концепций лидерства являются Л.Бернард, В. Бинхам, О. Тид, С. Килбоурн, Г. Юкл, Э. Гизелли, Р. Стогдилл, У.Беннис, К. Левин, М. Вудкок, Д. Френсис, 3. Фрейд и др.

Начиная с 1970-х годов интерес к изучению лидерства начал расти еще больше, о чем свидетельствует появление работ Д. Макгрегоpa, Р.Лайкерта,Р. Блейка и Д. Мутона, Ф. Фидлера, П. Херси и К. Бланшара, В.Врума и Ф. Йеттона, Т. Митчелла и Ф. Хауса, Р. Танненбаума и У.Шмидта и др. 
В современных условиях исследования лидерства сохраняют свою актуальность. Более того, в современных условиях темой лидерства заинтересовались не только специалисты социальной психологии, но и специалисты из смежных областей - индустриальной / организационной психологии и организационного поведения, социологических и экономических дисциплин, политологии и управления (менеджмента).

К сожалению, эта проблема в России ранее недооценивалась. Большинство работ в области исследования лидерства принадлежит западным ученым. Однако в настоящее время появляются труды российских ученых, затрагивающие проблемы психологии лидерства и менеджмента в повседневной работе руководителя.

Социально-психологическими исследованиями лидерства в малых группах занимались такие отечественные исследователи, как Б. Д. Парыгин (Парыгин, 1999), Н.С.Жеребова (Жеребова, 1999). Подход к рассмотрению лидерства через понятие личности лидера присущ таким отечественным авторам Т. В. Бендас (Бендас, 2009), Р.Л.Кричевский (Кричевский, 1993), Е. С. Яхонтова (Яхонтова, 2011) и др.

На русском языке в последние годы были опубликованы ряд книг по проблемам лидерства (Байхем, Смит, Пизи, 2002; Беляцкий, 2002; Зуб, Смирнов, 1999; Карделл, 2000; Кристофер, Смит, 2002; Кэ де Ври, 2003; Максвелл, 2001; Менегетти, 2001; Нефф, Ситрин, 2003).

Современное понимание лидерства, являясь продуктом (результатом) длительной эволюции, так называемых, классических теорий лидерства, предполагает интеграцию всех предшествующих подходов, методов и способов влияния на людей, сообразуясь с конкретной ситуацией, что позволяет трактовать лидерство не только как науку, но и как искусство (т. е. практику) управления. Поэтому, лидерство в последние годы - ведущая тема в теории и практике менеджмента. Более того, лидерство стало обязательной учебной дисциплиной в подготовке специалистов в области менеджмента.

Менеджмент использует лидерство как один из механизмов интеграции групповой деятельности для достижения целей организации и характеризует специфическую форму управленческих отношений в группе. Теория лидерства призвана давать ответ на многие вопросы управления: например, есть ли определенные качества, которые делают менеджеров эффективными лидерами? Рождаются лидерами, или действительно лидерство - навык, которому менеджер может и должен научиться? Как управлять лидерством в организации?

Существующие классические теории лидерства не дают однозначных ответов на эти и другие вопросы. Остается проблемой, также, отсутствие универсального определения базовых понятий «лидерство», «лидер», 
«лидерство менеджера». С начала ХХв. и по настоящий момент в научной литературе было предложено свыше 350 определений лидерства. Этот факт хорошо иллюстрирует, насколько сложна его природа. Понимание феномена лидерства характеризуется сложностью, разнообразием и изменчивостью с течением времени, поэтому оно не допускает какого-либо унифицированного определения.

Множественность определений понятия «лидерство» обусловлено разными подходами к анализу его предмета. Как показывает исследование литературы, предметом (или признаками) лидерства чаще всего выступают:

отношения доминирования и подчинения;

процесс организации группы;

процесс влияния и взаимовлияния;

процесс мотивации;

способ воздействия;

осуществление полномочий власти;

способности, качества и поведение лидера;

механизм интеграции групповой деятельности другие.

Кроме того, при анализе понятия «лидерство» часто учитывается не только его предмет, но и «угол зрения» на этот предмет. Это порождает разнообразие подходов и, как следствие, определений понятия лидерства, что представляется положительной тенденцией, позволяющей, с одной стороны, более полно отразить сущность этого сложного социальнопсихологического явления. С другой - такое разнообразие создает трудности в понимании и, главное, в практическом использовании лидерства, как инструмента управления. В этой связи ряд исследователей (Яхонтова, 2011; Беляева, 2008; Пфеффер, 2014; Алыфанов, 1991 и др.) утверждают о наличии кризисной ситуации в области психологических исследований лидерства, что эти исследования в современных условиях зашли в тупик. По этой причине они считают, что следует вновь обратиться к анализу самого базового понятия - «лидерство».

Быстрый рост эмпирических исследований лидерства, отмечает С. А. Алыфанов, происходил на фоне отсутствия солидного теоретического обеспечения, в условиях, когда даже само понятие «лидерство» не было соответствующим образом теоретически интерпретировано, что привело к парадоксальной ситуации, когда возникло столько же определений лидерства, сколько существует людей, пытающихся определить это понятие (Алыфанов, 1991). По мнению автора, выход из создавшегося положения заключается в необходимости, во-первых, разграничить понятия «лидерство» и «руководство», «лидерство» и «власть» и, во-вторых, расширить и углубить теоретическую платформу изучения лидерства за счет экспан- 
сии в эту область понятий и концептуальных схем из более глобальных теоретических подходов.

В этой связи ряд авторов отмечает, что методологической основой исследований современного понимания лидерства в менеджменте должен стать дуалистический подход, рассматривающий лидерство как явление, имеющее двойственную природу (Беляева, 2008; Беляцкий, 2002; Зуб, Смирнов, 1999). По их мнению, дуалистический подход позволяет определить современное понимание лидерства как:

1) ведущее положение отдельной личности, социальной группы, обусловленное более эффективными результатами деятельности;

2) процессы внутренней самоорганизации и самоуправления группы, коллектива, обусловленные индивидуальной инициативой их членов.

Первое определение показывает субъективный характер данного понятия: менеджер, достижения которого признает определенная группа людей, может быть для этих людей лидером, и в то же время другая группа может отрицать его лидерство, если не рассматривает соответствующие достижения как выдающиеся. Менеджер в своем влиянии на работу подчиненных и построении отношений с ними использует и полагается, прежде всего, на должностную основу власти и источники, ее питающие.

Второе определение, в отличие от первого, отражает динамизм процесса лидерства в менеджменте. Действительно, лидерство - это не только положение личности или группы, но еще и процесс вовлечения последователей в деятельность, направленную на достижение определенных целей. Лидерство как специфический тип отношений управления основывается больше на процессе социального воздействия, а точнее, взаимодействия в организации. Этот процесс является гораздо более сложным, требующим высокого уровня взаимозависимости его участников.

На основе анализа существующих определений лидерства может быть предложено следующее авторское определение понятия «лидерство менеджера»: лидерство менеджера - процесс, в ходе которого менеджер как лидер организации для достижения ее целей вместе с ее сотрудниками создает общее их видение будущего и организует взаимодействие, вовлекающее сотрудников организации в реализацию данных целей.

Естественно, что это определение также не претендует на универсальность. Однако по сравнению с существующими современными определениями его можно назвать более демократичным и процессуальным, подчеркивающим вовлеченность сотрудников и наличие обратных связей, что имеет существенное значение для практики управления.

Сегодня менеджмент нуждается в дальнейшем изучении и практическом использовании концепции лидерства для выработки методов эффективного руководства, отбора и формирования эффективных лидеров. 
Ученых и практиков в сфере менеджмента, по-прежнему, волнует вопрос: кто такой современный менеджер? Каков менеджер будущего? Как же надо готовить менеджера, способного работать в новых условиях?

Ответы на эти вопросы пытаются найти многие отечественные и зарубежные исследователи и практики менеджмента (в т. ч. и авторы данной статьи). Наибольшую популярность и признание в последние годы получила точка зрения классика современного менеджмента - Питера Друкера. В ряде его работ, например, «Менеджмент. Вызовы XXI века», «O профессии менеджера», «Практика менеджмента», он неоднократно подчеркивает мысль, что менеджеры не должны быть только лишь технократами. Они обязаны понимать социальное значение своей деятельности. «Знание и понимание человека, форм его поведения в социальной организации важнейший элемент управленческой культуры и суть менеджеральной революции XXI века (Друкер, 2003).

Говоря о менеджере будущего, П. Друкер утверждает, что менеджер, как профессиональный управляющий, прежде всего, должен уметь управлять социально-психологическими процессами, происходящими в организации. Он должен научиться мотивировать людей создавать единую команду, выполнять лидерские функции. По его мнению, в профессиональной подготовке менеджера XXI века потребуются:

1) Общее образование. Менеджер будущего не может оставаться «узким» специалистом в области управления. Ему потребуются широкое, прежде всего, гуманитарное образование;

2) Профессиональная подготовка в области менеджмента. Эта подготовка должна быть направлена, во-первых, на формирование знаний и умений выполнять профессиональную работу в управлении, во-вторых, на формирование способности менеджера работать с людьми и управлять самими собой;

3) В области формирования личности менеджера важнейшим фактором успеха менеджера станут не только знания, компетенция и квалификация, но и его «личностные качества, такие как дар предвидения, лидерство, организаторские и креативные способности и другие (Друкер, 2012).

Таким образом, современный менеджер представляется, прежде всего, как специалист в области управления отношениями людей в процессе их совместной деятельности, которые в менеджменте, по сути, являются отношениями лидерства. На наш взгляд, эти теоретико-методологические установки имеют большое значение для определения направлений и содержания практической профессиональной подготовки современных специалистов в области менеджмента.

Эти требования к профессиональной компетенции менеджера определенным образом отражены в современном образовательном стандар- 
те, среди которых требование быть компетентным в сфере управления персоналом, отбора, подготовки и использования кадров, мотивации, лидерства, разрешения конфликтов, совершенствования психологического климата в трудовом коллективе.

Однако, следует заметить, что в образовательном стандарте отсутствуют требования к формированию личностных качеств менеджера как лидера, что, на наш взгляд, является недостатком.

Учитывая важность и актуальность проблемы лидерства для профессиональной подготовки будущих руководителей, вузы должны предвидеть грядущую смену ролей менеджера и своевременно вносить необходимые изменения в учебные планы профессиональной подготовки этих специалистов. Формирование лидерских качеств и навыков поведения менеджера должно стать важнейшей задачей образовательного процесса в вузе. Главное направление этой подготовки будущего менеджера - помочь студентам проанализировать и оценить свой лидерский потенциал, научиться вести себя в группе и действовать как лидер.

Определенный опыт накоплен в Московском гуманитарном университете на кафедре менеджмента в ходе преподавания учебной дисциплины «Лидерство». Так, в 2013-2014 гг. в ходе образовательного процесса, преподавателями кафедры был реализован исследовательский проект «Лидерство менеджера», участниками которого являются авторы данной статьи.

Исследования уровня развития лидерских качеств студентов проводились на факультете экономики и управления. В ходе проведенного исследования были обследованы 64 студента 2-го курса. Из них дневное обучение -42 чел., заочное и вечернее -22 чел. Возрастная категория студентов 18-22 года. Стаж работы и опыт управленческой деятельности до 2 лет имеют 16 человек (заочное обучение).

Цель исследования состояла в том, чтобы на основе диагностики уровня развития лидерских качеств у обучаемых студентов, использования комплекса упражнений, тренингов, рекомендаций, обеспечить их развитие в соответствии с требованиями профессии менеджера.

Задачами исследования были:

1. Формирование у студентов необходимых знаний, навыков и умений лидерского поведения в ходе изучения учебной дисциплины «Лидерство»;

2. Проведение диагностики уровня развития лидерских качеств у студентов учебной группы;

3. Доведение и усвоение обучаемыми основных практических рекомендаций по самостоятельной работе над развитием лидерских качеств (в соответствии с результатами диагностики);

4. Проведение повторного обследование студентов этих же групп на 
старших курсах.

В ходе исследования были использованы методики:

-Диагностики лидерских способностей;

-Тренинги, деловые игры;

• Наблюдения за проявлением лидерства в группе;

- Анкетирование.

Особое значение в ходе исследования уделялось использованию методов диагностики функционального лидерства в малых группах, так как эти методы позволяют в реальных социальных условиях реализовывать статус лидера группы (не бывает лидера вне группы). При применении методики «Социально-психологическая диагностика развития личности и малых групп» (Мануйлова, 2002) учитывалось, что статусом лидера обладает тот, кто набирает более 50\% выборов от их общего количества. Статус предпочитаемого имели те, кто собирает от 20 до 50\% общего количества выборов. Статусом аутсайдера обладали те, которые не получили выборов или имеют их незначительное количество (до 20\%). Определение статуса непредпочитаемого не проводилось.

При анализе сводной таблицы результатов внимание акцентировать на том, что статусы индивидов в группе всегда динамичны, ибо зависят от направленности личности каждого, его ведущих психологических характеристик, степени включенности в совместную деятельность, активной жизненной позиции. Поэтому у каждого есть возможность изменить свой статус в лучшую сторону и тем самым занять более высокое, комфортное положение в системе межличностных отношений.

Повторное исследование студентов в группе позволило увидеть динамику межличностных отношений, складывающихся в группе на протяжении определенного периода времени.

Полученные результаты исследования:

1. Результаты повторного исследования студентов, старших курсов тех же учебных групп методом анкетирования показали, что большинство опрошенных (75\%) продолжали самостоятельную работу по развитию лидерских качеств, используя при этом полученные в ходе изучения курса «Лидерство» знания, навыки и умения. Все из них отметили в целом положительное сдвиги в своем личностном развитии и формировании профессиональных качеств менеджера. По мнению опрошенных, это проявилось:

в более осознанном и углубленном понимании природы и механизма функционирования лидерства менеджера (56\%);

в росте навыков и умений выбора оптимального лидерского стиля поведения в группе (67\%);

в ощущении большей уверенности в своих силах при принятии опре- 
деленных решений (90\%);

в повышении активности при обсуждении учебных вопросов на семинарах, дискуссиях (83\%);

в повышении результативности образовательного процесса в вузе в целом и делового общения вне его (86\%);

2. На основе обобщения опыта преподавания учебного курса «Лидерство», авторами было разработано и опубликовано учебное пособие «Лидерство менеджера», которое состоит их двух частей: теоретической и практической (практикума) (Колношенко, Колношенко, 2014). Первая часть уже опубликована, вторая планируется кафедрой к изданию в ближайшем будущем.

Во второй части учебного пособия «Лидерство менеджера» планируется включить материалы, содержащие проверенные практикой рекомендации по развитию лидерских качеств у студентов - будущих менеджеров. В этой связи в практической части учебного пособия планируется использовать материалы и рекомендации, разработанные рядом известных отечественных и зарубежных исследователей и специалистов (Вачков, 1999; Панкрухин, 2007; Кричевский, Дубровская, 1991; Беннис, Шепард, 1984) и др. Эти материалы могут быть использованы как студентами, так и преподавателями при изучении различных теоретических и практических проблем лидерства.

Анализ литературы показывает, что основными направлениями развития лидерских качеств у будущих менеджеров должны стать:

- Выработка личной мотивированности, устойчивого желания быть лидером, уверенности в себе, готовности принимать решения и брать на себя ответственность, последовательности и упорства в реализации общих целей, осознания собственной силы, веры в достижение цели, энтузиазма и т. п. Эта группа качеств характеризует различные параметры активности лидера. Процедуры индивидуальной самомотивации достаточно разработаны в соответствующей литературе и широко используются в практике менеджмента;

- Развитие индивидуальных интеллектуальных и нравственных лидерских качеств. К таким качествам относятся, прежде всего, профессиональная компетентность, порядочность (честность, соблюдение общепринятых нравственных норм), без которой, как правило, трудно, а то и совсем невозможно завоевать авторитет, развитый интеллект, проявляющийся в аналитичности, быстроте понимания сути проблемы, гибкости ума, предусмотрительности, умении планировать и ставить цели и т. д.;

- Обеспечение социальной компетентности лидера и его доброжелательности в отношениях с членами группы. Это предполагает культуру общения, умение ясно и четко выражать мысли, корректно выслушивать 
сотрудников, делать замечания, давать советы, внимательность, уважение достоинства других людей, умение понимать их, проникаться их заботами и проблемами, оказывать им поддержку и т. п.;

-Приобретение умения и навыков быстро и правильно оценивать ситуацию, знать и учитывать особенности, интересы, запросы и ожидания всех членов группы. Повторяющиеся неудачи обычно ведут к утрате веры в лидера;

- Непрерывное самосовершенствование. Важно искать способы самосовершенствования - чтение, прохождение дополнительного курса обучения. Для большинства людей характерна тенденция к ограничению вчерашними знаниями, а не воспитанию в себе духа непрерывного самосовершенствования. Однако если не совершенствовать себя, то трудно побудить других заняться этим делом;

- Самокритичность, толерантность (терпимость), признание заслуг других и их равного права на самовыражение. Важно уметь ценить различия взглядов. Следует исходить из того, что ваш метод не является «единственно правильным», необходимо рассматривать новые альтернативы как захватывающие, а не как угрожающие;

- Забота о физическом здоровье, интеллектуальном и духовном развитии. Требуется следить за своим физическим состоянием с помощью упражнений, чтобы сохранить здоровье, за интеллектуальным - с помощью чтения; за духовным - с помощью медитирования / молитвы, умственного сосредоточения и психологического настроя на что-либо при полном отрешении от всего остального.

Способами развития лидерских качеств менеджера могут быть:

1. Социально-психологическая диагностика развития личности (Фетискин, Козлов, Мануйлов, 2002);

2. Практические упражнения, относящихся к начальной ступени развития лидерского потенциала;

3. Тренинги личностного роста и лидерского саморазвития (Вачков, 1999; Гусарева, 2006).

Цель итогового занятия - разработать дальнейшую программу действий. На этом этапе следует соединить в одно целое все конкретные шаги, о которых выполнялись ранее. Они должны образовать программу самостоятельного развития лидерских качеств.

При этом, важно учитывать, что ключевыми элементами развития лидерских качеств являются:

1) знание теоретических принципов;

2) максимум практики;

3) самостоятельное обучение посредством обратной связи (анализ успехов и неудач). 
Таким образом, на основе анализа проблем теории и практики лидерства в менеджменте можно сделать следующие выводы.

Во-первых, данная проблема представляется по-прежнему актуальной. Обзор основных направлений развития теории лидерства показывает, что исследования в этой области менеджмента ведутся широким фронтом, захватывая все новые разделы и открывая новые темы. Основной причиной не только не прекращающихся, но и расширяющихся изысканий в области лидерства, по нашему мнению, является его синтетическая природа.

Во-вторых, теоретическую основу лидерства составляют его классические теории: теории лидерских качеств, лидерского поведения и ситуационная теория лидерства. Вместе с тем в современных условиях эти теории требуют дальнейшего своего развития на основе их интеграции.

В-третьих, поскольку лидерство является важнейшей характеристикой профессионализма менеджера и значимость проблемы его лидерства в последние годы только возрастает, в дальнейшем важно продолжить исследования практического использования концепции лидерства в области менеджмента. Этому можно было бы посвятить специальное диссертационное исследование. Приоритетными направлениями такого исследования могли бы быть проблемы развития у менеджера лидерских качеств и навыков, оптимизации его лидерского стиля поведения, эффективности управления лидерством в организации.

B-четвертых, возрастающие потребности практики менеджмента обусловливают необходимость шире и глубже отражать в содержании и методике образовательного процесса в вузе социально-психологические, управленческие и другие аспекты лидерства менеджера. Поскольку, как отмечалось ранее, лидерство - явление сложное и синтетическое, было бы целесообразным со студентами вузов, обучающимся по направлению менеджмент, управление персоналом, проводить комплексные образовательные курсы, большая часть времени которых была бы посвящена диагностике лидерских качеств обучаемых, проведению с ними тренингов, деловых игр, составлению индивидуальных программ развития лидерства. В проведении таких занятий следовало бы привлечь преподавателей различных кафедр, прежде всего, кафедр социологии, психологии, менеджмента и других.

\section{СПИСОК ЛИТЕРАТУРЫ}

Алыфанов, С. А. (1991) Основные направления анализа лидерства // Вопросы психологии. № 3. С. 90-96.

Байхем, В. С., Смит, О. Б., Пизи, М. Дж. (2002) Воспитай своего лидера. 
Как находить, развивать и удерживать в организации талантливых руководителей. М. : Вильямс.

Беляева, А. А. (2008) Теории лидерства на современном этапе // Вестник КАСУ. №4. С. 12-23.

Беляцкий, Н. П. (2002) Менеджмент. Основы лидерства. Минск : Новое знание.

Бендас, Т. В. (2009) Психология лидерства. Учебное пособие. СПб. : Питер.

Беннис, У., Шепард, Г. (1984) Теория группового развития // Современная зарубежная социальная психология. М. : Изд-во Московского университета. С. 142-161.

Вачков, И. В. (1999) Основы технологии группового тренинга. М. : Изд-во «Ось-89».

Гусарева, Н. Б. (2006) Сборник тренингов, деловых игр и диагностических материалов по управлению персоналом : учебное пособие. М. : Издательство МосГУ.

Друкер, П. (2012) Менеджмент. Вызовы XXI века. М. : Манн, Иванов и Фербер.

Друкер, П. (2008) О профессии менеджера. М. : Вильямс.

Друкер, П. (2003) Практика менеджмента. М. : Вильямс.

Жеребова, Н. С. (1999) Лидерство в малых группах, как объект социально-психологи-ческого исследования. Самара.

Зуб, А. Т., Смирнов, С. Г. (1999) Лидерство в менеджменте. М. : Воскресенье.

Карделл, Ф. (2000) Психотерапия и лидерство. СПб. : Речь, 1999.

Колношенко, В. И., Колношенко, О. В. (2014) Лидерство : учебное пособие / отв. ред. Ю. Н. Царегородцев. М. : МосГУ.

Кристофер, Э., Смит, Л. (2002) Тренинг лидерства. СПб. : Питер.

Кричевский, Р. Л. (1993) Если вы - руководитель. Элементы психологии менеджмента в повседневной работе. М. : Дело.

Кэ де Ври М. (2003) Мистика лидерства: развитие эмоционального интеллекта. М. : Альпина Паблишер.

Максвелл, Д. (2001) 21 неопровержимый закон лидерства. Минск : Попурри.

Мануйлова, Г. М. (2002) Социально-психологическая диагностика развития личности и малых групп. М. : Изд-во Института Психотерапии.

Менегетти, А. (2001) Психология лидера. 3-е изд. М. : Онтопсихология.

Нефф, Т. Д., Ситрин, Д. М. (2003) Уроки лидеров. М. : Изд-во АСТ.

Панкрухин, А. П. Диагностика и развитие лидерских способностей [Электронный ресурс] // Элитариум. 2.0. URL: http://www.elitarium. 
ru/2007/08/27/razvitie_liderskikh_sposobnostejj.html

[архивировано

B Website] (дата обращения 20.11.2014).

Парыгин, Б. Д. (1999) Социальная психология. проблемы методологии, истории и теории. СПб. : ИГУП.

Пфеффер, Дж. (2014) Власть, влияние и политика в организациях. М.: ЛитРес.

Фетискин, Н. П., Козлов, В. В., Мануйлов, Г. М. (2002) Социальнопсихологическая диагностика развития личности и малых групп. М. : Издво Института Психотерапии.

Яхонтова, Е. С. (2011) Новая парадигма лидерства в экономике знаний и кризис лидерства в России // Менеджмент сегодня. № 2. С. 66-78.

Колношенко Владимир Иванович - кандидат исторических наук, доцент кафедры менеджмента Московского гуманитарного университета, доцент, заслуженный работник культуры РФ. Адрес: 111395, Россия, г. Москва, ул. Юности, д. 5. Тел.: +7 (499) 374-70-13. Эл. адрес: kaf.76@mail.ru>

Колношенко Олег Владимирович- кандидат педагогических наук, доцент кафедры менеджмента Московского гуманитарного университета доцент. Адрес: 111395, Россия, г. Москва, ул. Юности, д. 5. Тел.: +7 (499) 374-70-13.Эл. адрес: kaf.76@mail.ru

Kolnoshenko Vladimir Ivanovich, Candidate of History, Associate Professor, Department of management, Moscow University for the Humanities, Honored Worker of Culture of the Russian Federation. Postal address: 5 Yunosti St., 111395 Moscow, Russian Federation. Tel.: +7 (499) 374-70-13. E-mail: kaf.76@mail.ru

Kolnoshenko Oleg Vladimirovich, Candidate of Pedagogy, Associate professor, Department of management, Moscow University for the Humanities. Postal address: 5 Yunosti St., 111395 Moscow, Russian Federation. Tel.: +7 (499) 374-70-13.E-mail:kaf.76@mail.ru 